\title{
Pemahaman Rumah Dan Pakaian Adat Indonesia Berbasis Multimedia Pada Anak Sekolah Dasar
}

\author{
Ari Yunus Hendrawan ${ }^{1 *}$, Putri Novitasari ${ }^{1}$ \\ ${ }^{1)}$ STIMIK AKI PATI, Kabupaten Pati Jl. Kamandowo No. 13 Pati. 59163. Jawa \\ Tengah, Indonesia \\ *Email: aritubil@gmail.com
}

Diterima: 12 Oktober 2020; Disetujui: 1 Desember 2020; Diterbitkan: 3 Desember 2020

\begin{abstract}
ABSTRAK
Sistem komputerisasi saat ini sudah menjadi kebutuhan manusia untuk membantu dalam menyelesaikan permasalahan. Pada dunia pendidikan komputerisasi bisa digunakan untuk menyampaian materi yang sangat efektif. Umumnya Sekolah Dasar dalam penyampaian materi masih bersifat manual yaitu dalam penyampaian materi masih menggunakan media papan tulis yang kurang efektif. Tujuan dari penelitian untuk menghasilkan media pembelajaran interaktif, supaya kegiatan belajar mengajar lebih efektif dan efesien agar penyampaian materi kepada siswa bisa tersampaikan dengan baik. Aplikasi multimedia ini dibuat dengan tampilan menarik agar dapat membuat anak-anak tertarik dalam mengenal dan memahami rumah dan pakaian adat di Indonesia. Penelitian ini menggunakan metode pengembangan perangkat lunak Multimedia Development Life Cycle(MDLC). Pada kegiatan belajar mengajar terutama guru dalam penyampaian materi dan siswa bisa menerima materi dengan lebih baik.
\end{abstract}

Kata kunci : pembelajaran interaktif, multimedia development life cycle, rumah dan pakaian adat

\section{PENDAHULUAN}

Pada zaman sekarang ini, perubahan teknologi berkembang begitu pesat. Perubahan tersebut tidak dipungkiri lagi sudah merambah disegala bidang, termasuk di bidang pendidikan. Dalam perubahan tesebut telah berpengaruh pada perkembangan pembelajaran di bidang pendidikan.

Di tahap pendidikan usia sekolah dasar, siswaa cenderung tertarikpada permainan yang didalamnya terdapat objek desain yang menarik dan mudah dipelajari oleh anak usia sekolah dasar. Sehingga pada siswa sekolah dasar, untuk lebih mudah guru memberikan materi pelajaran tentang pemahaman rumah dan pakaian adat di indonesia yang dirancang dalam sebuah desain dan permainan edukatif yang menarik berbasis multimedia. Oleh karena itu dalam memberikan desain dan permainan edukatif, siswa secara tidak langsung akan menerima isi materi yang terdapat dalam permainan tersebut [1]. 
Dikarenakan minimnya fasilitas dan alat peraga yang menghambat proses penyampaian materi belajar-mengajar di sekolah dasar, akan lebih efektif dan efesien jika menggunakan media pembelajaran interaktif berbasis multimedia dengan bentuk sebuah desain dan permainan edukatif yang menarik.

Penggabungan antara teknologi dengan pemahaman adat indonesia merupakan solusi yang tepat, supaya diera globalisasi sekarang ini anak-anak bisa mengenal dan memahami rumah serta pakaian adat indonesia . Oleh karena itu, guru perlu membuat dan memiliki pembelajaran interaktif menggunakan komputer yang berbasis multimedia dalam penyampaian materi khususnya tentang pemahaman rumah dan pakaian adat Indonesia.

\section{TINJAUAN PUSTAKA}

Didalam penelitian diperlukan dukungan dari hasil penelitian yang telah ada pada sebelumnya, yang berkaitan dengan penelitian ini.

Menurut dari penelitian Jupriyanto (2013) yang berjudul "Pengenalan Adat Tradisional Indonesia Berbasis Multimedia Pada Madrasah Ibtidaiyah Muhammadiyah (Mim) Ngadirejan" berpendapat bahwa media interaktif lebih efektif dan efisien dibanding media-media sebelumnya karena sangat membantu guru dan siswa dalam kegiatan belajar-mengajar di sekolah [2] .

Selanjutnya dari penelitian Gamrina Sagala (2017) dari jurnalnya yang berjudul "Perancangan Aplikasi Pembelajaran Pakaian Adat Asli Indonesia Berbasis Multimedia Dan Web Menerapkan Metode Computer Assisted Instruction (Cai)" mengungkapkan Proses pembelajaran yang dibuat akan lebih menarik apabila diterapkannya suatu metode sebagai alat bantu didalam melakukan pembelajaran menggunakan metode CAI (Computer Assisted Instruction), yang didalamnya terdapat materi, drill/practice, simulasi dan game. Penerapan 'metode CAI (Computer Assisted Instruction) dalam proses pembelajaran dapat memberikan kemudahan dalam proses pembelajaran. Penerapan metode dengan mengurutkan materi dan soal yang akan diakses oleh peserta. Dimana bentuk pembelajaran lebih terurut dan mudah untuk dipahami [3].

Kemudian dari penelitian Ivenulut Rizki (2016) yang berjudul "Pengembangan Game Edukasi Pengenalan Budaya Indonesia "Jelajah" Berbasis Android" memaparkan Game merupakan salah satu media alternatif untuk memperkenalkan budaya Indonesia karena mudah diterima di semua kalangan dan sangat diminati oleh anak-anak. Membuat game pengenalan budaya Indonesia dengan memanfaatkan teknologi saat ini yaitu smartphone android dirancang dalam bentuk gambar dan menerapkan Algoritma Fisher Yates Shuffle untuk pengacakan posisi rintangan dan alat musik membuat pengenalan budaya Indonesia khususnya alat musik dan pakaian adat menjadi menyenangkan. 
Dengan ini maka pengaruh media interaktif khususnya multimedia sangat membantu guru dan siswa dalam kegiatan proses belajar mengajar yang lebih efektif, efisien dan modern [4].

\section{LANDASAN TEORI \\ Multimedia}

Multimedia merupakan teknologi yang menggabungkan antara teks, seni, suara, gambar, animasi dan video yang disampaikan dengan komputer sehingga lebih menarik dan interaktif. Multimedia terdiri dari animasi, text, gambar, suara, dan video [5].

\section{Macromedia Flash 8}

Macromedia Professional Flash 8 adalah sebuah program animasi yang telah banyak digunakan oleh para animator untuk menghasilkan animasi yang professional. Macromedia Proffesional Flash 8 merupakan sebuah program aplikasi yang digunakan untuk membuat animasi vektor dan bitmap yang sangat menakjubkan untuk keperluan pembangunan situs web yang interaktif dan dinamis. Selain itu aplikasi ini juga dapat digunakan untuk memuat animasi logo, movie, game, pembuatan navigasi pada situs web, banner, tombol animasi, menu interaktif, interaktif form isian, e-card, screen server, dan pembuatan situs web atau pembuatan aplikasi-aplikasi web lainnya [6].

Keunggulan lain yang dimiliki program Macromedia Professional Flash 8 antara lain:

1. Mampu membuat tombol interaktif dengan sebuah movie atau objek yang lain.

2. Macromedia Professional Flash 8 mampu membuat perubahan transparansi warna dalam movie.

3. Macromedia Professional Flash 8 mampu membuat perubahan animasi dari satu bentuk ke bentuk lain dan mampu membuat gerakan animasi dengan mengikuti alur yang telah ditetapkan.

4. Macromedia Professional Flash 8, file dapat dikonversi dan dipublikasikan (publish) ke dalam beberapa tipe file aplikasi diantaranya .exe, .gif, .jpg, .png, .mov.

5. Dapat mengolah dan membuat animasi berbasis vector memiliki fleksibilitas dalam pembuatan objek-objek vector.

\section{Rumah Adat}

Rumah adat adalah bangunan yang memiliki cirikhas khusus, digunakan untuk tempat huniann oleh suku bangsa tertentu. Rumah adat salah satu respresentasi kebudayaan yang paling tinggi dalam sebuah komunitas suku/masyarakat. Keberadaan rumah adat di indonesia sangat beragam dan mempunyai arti yang penting dalam perspektif sejarah, warisan, dan kemajuan masyarakat dalam sebuah peradaban [7]. 


\section{Pakaian Adat}

Pakaian adat merupakan suatu pakaian yang digunakan masyarakat di suatu daerah tertentu saat melakukan acara, kelahiran, ritual, penyambutan tamu, pagelaran seni budaya. Pakaian adat juga dijadikan simbol kebudayaan dari suatu daerah. Dari pakaian adat juga masyarakat dapat menunjukkan nama daerah yang merupakan asal dari pakaian adat tersebut. Setiap daerah yang berada di Indonesia memiliki pakaian adat yang berbeda-beda. Pakaian adat tersebut biasanya digunakan dalam kegiatan memperingati hari besar seperti kelahiran, pernikahan, kematian, serta hari-hari besar keagamaan. Sebagai simbol, pakaian adat memang dijadikan penanda dalam suatu kegiatan [3]

\section{METODE PENELITIAN}

\section{Populasi dan Sampel Penelitian}

1. Populasi penelitian

Dalam penyusunan makalah ini, kami membatasi ruang lingkup populasi penelitian. Populasi dalam ruang lingkup lebih terbatas yang digunakan dalam proses penelitian ini adalah anak-anak Sekolah Dasar.

2. Sampel Penelitian

Dalam penyusunan makalah ini, kami menggunakan sampel penelitian dalam batas populasi penelitian yaitu anak-anak Sekolah Dasar. Sampel penelitian yang dipakai adalah anak-anak Sekolah Dasar yang berjumlah 30 orang.

\section{Waktu dan Tempat Pelaksanaan Penelitian}

1. Waktu Pelaksanaan Penelitian

Kami mengadakan penelitian yang dilaksanakan pada hari Selasa, 5 November 2019 sampai dengan Kamis, 7 November 2019.

2. Tempat Pelaksanaan Penelitian

Kami mengadakan penelitian yang dilaksanakan di Sekolah Dasar.

\section{Metode Penelitian dan Alat Pengumpulan Data}

1. Metode Penelitian

a. Observasi

Observasi langsung di tempat penelitian dengan melakukan pengamatan langsung terhadap sistem yang sedang berjalan sesuai alur data dan prosedur di lingkungan sekitar Sekolah Dasar. 


\section{b. Interview}

Interview atau wawancara merupakan pencarian data melalui proses tanya jawab kepada orang yang terlibat langsung dengan Sekolah Dasar.

c. Studi Pustaka

Melakukan studi kepustakaan dengan mengumpulkan data dan informasi mengenai prosedur sistem yang telah ada SD, analisa perancangan sistem berorientasi objek dan bahasa pemrograman yang dapat digunakan sebagai acuan pembahasan dalam masalah ini.

2. Alat Pengumpulan Data

Kami menggunakan alat-alat bantu untuk memperoleh data yang dibutuhkan. Alat-alat yang digunakan berupa angket, teori-teori yang didapat dari internet.

\section{Cara Penggunaan Aplikasi}

Berikut ini merupakan cara penggunaan aplikasi pengengenalan rumah dan pakaian adat Indonesia:

1. Buka playstore terlebih dahulu untuk mendownload aplikasi pemahaman rumah dan pakaian adat Indonesia.

2. Setelah selesai mendownload, buka aplikasi tersebut.

3. Kemudian akan menuju beranda aplikasi tersebut dan terdapat dua menu yaitu menu belajar dan menu game. Kemudian pilih salah satu.

4. Apabila memilih menu belajar maka akan muncul menu pakaian dan menu rumah adat. Disana terdapat gambar dan penjelasan mengenai pakain dan rumah adat.

5. Kemudian jika memilih menu game maka akan muncul game ayo tebak mengenai rumah dan pakaian adat Indonesia. Disitu akan muncul timer dan scor untuk mengetahui seberapa besar kemampuan si pengguna dalam memahami rumah dan pakaian adat Indonesia.

6. Selesai.

\section{HASIL DAN PEMBAHASAN}

\section{Pembahasan}

Aplikasi yang penulis rancang menggunakan Macromedia Flash Profesional CS3 yang akan direalisasikan dalam bentuk animasi. Animasi ini meliputi beberapa pilihan menu, diantaranya adalah menu tampilan daftar tempat daerah, menu game serta menu quis. Pada aplikasi ini terdapat menu quis yang bertujuan untuk mengetahui sejauh mana anak-anak memahami terhadap rumah dan pakaian adat indonesia yang ada dalam aplikasi ini.

Tahapan dalam pembuatan aplikasi ini dimulai dari tahap konsep sampai dengan tahap distribusi. Berikut adalah penjelasan dari masing-masing tahapan tersebut.

a. Konsep(Concept)

Tahap awal dalam pembuatan aplikasi ini adalah menentukan konsep. Aplikasi pemahaman rumah dan pakaian adat dibuat dengan maksud sebagai salah satu 
media pembelajaran bagi anak-anak agar mereka mengetahui rumah dan pakian adat di indonesia [8].

b. Perancangan(Desain)

Berikut adalah desain storyboard dari aplikasi pemahaman rumah dan pakian adat Indonesia :

1. Storyboard Menu utama

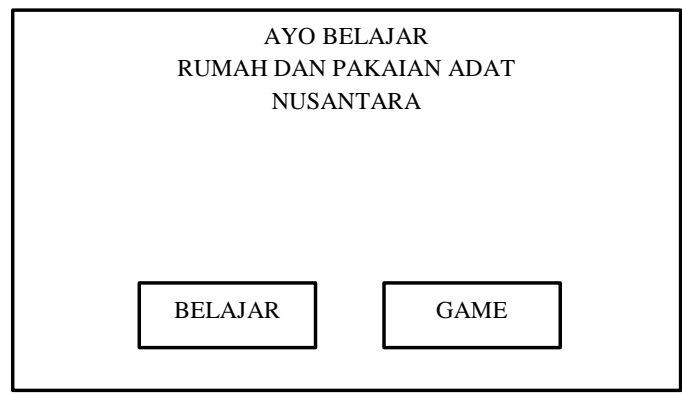

2. Storyboard Belajar

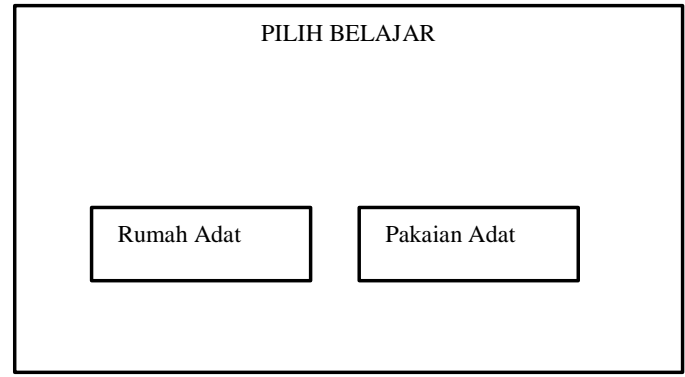

3. Storyboard Game

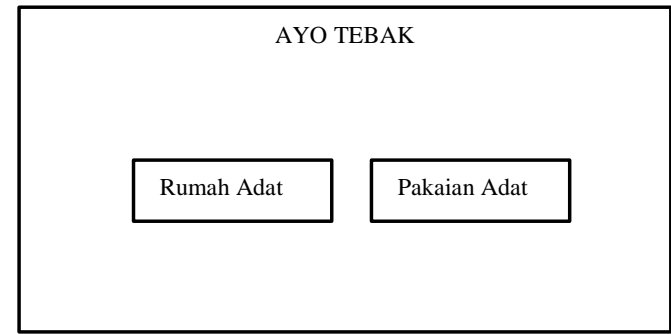

4. Storyboard belajar rumah adat

\begin{tabular}{|c|}
\hline RUMAH ADAT \\
Jawa Tengah \\
IMAGE \\
Kebaya \\
\hline
\end{tabular}


5. Storyboard game rumah adat

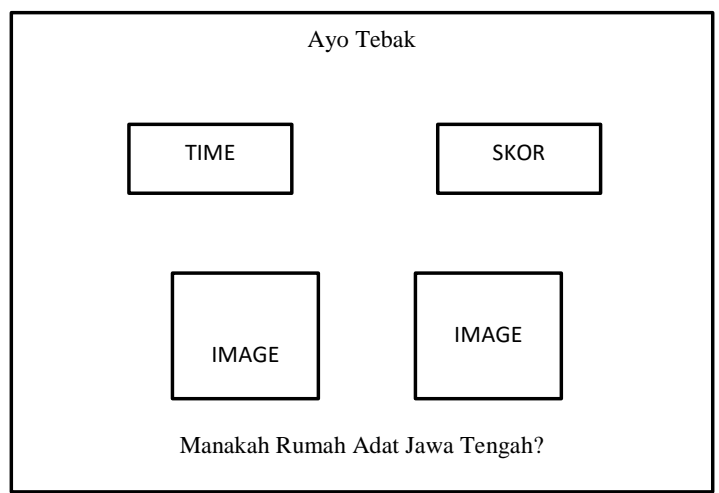

c. Pengumpulan Bahan (Material Collecting)

Bahan yang dibutuhkan untuk pemahaman rumah dan pakaian adat Indonesia yaitu berupa gambar yang penulis buat menggunakan Corel Draw.

d. Pembuatan(Assembly)

Tahap ini berupa tampilan aplikasi dari desain yang akan diaktualisasikan kepada pengguna. Menu yang ada dalam aplikasi ini dirancang sedemikian rupa dengan rancangan yang menarik, interaktif dan user friendly.

\section{Implementasi}

1. Menu Utama

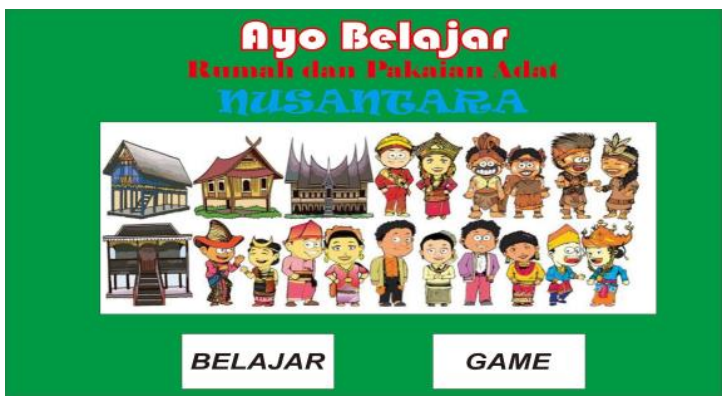

Gambar Menu Utama

2. Menu Belajar

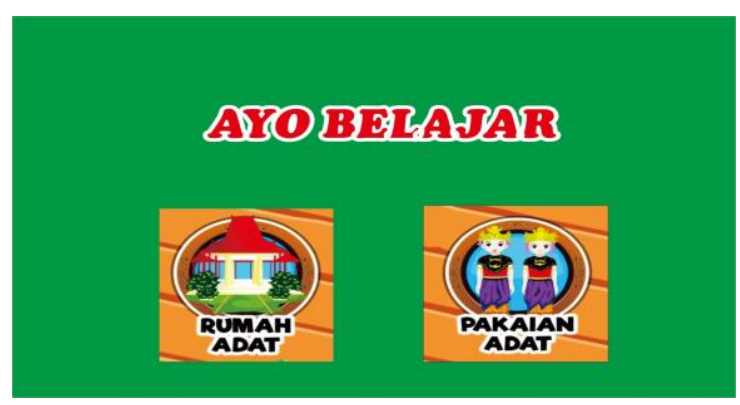

Gambar Menu Belajar 


\section{Menu Game}

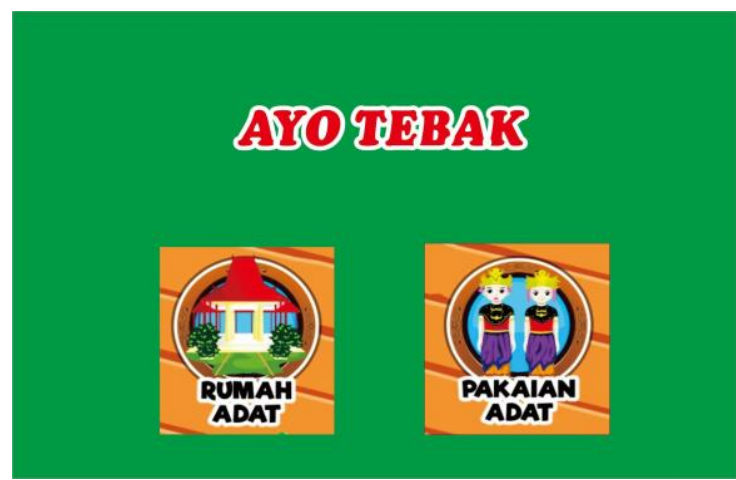

Gambar Menu Game

4. Isi Menu Belajar Pakaian Adat

\section{PabaianAdat}

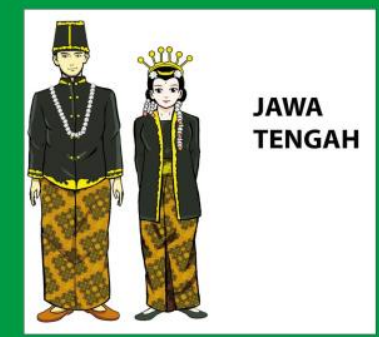

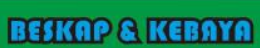

Gambar Isi Menu Belajar Pakaian Adat 
5. Isi Menu Game Rumah Adat

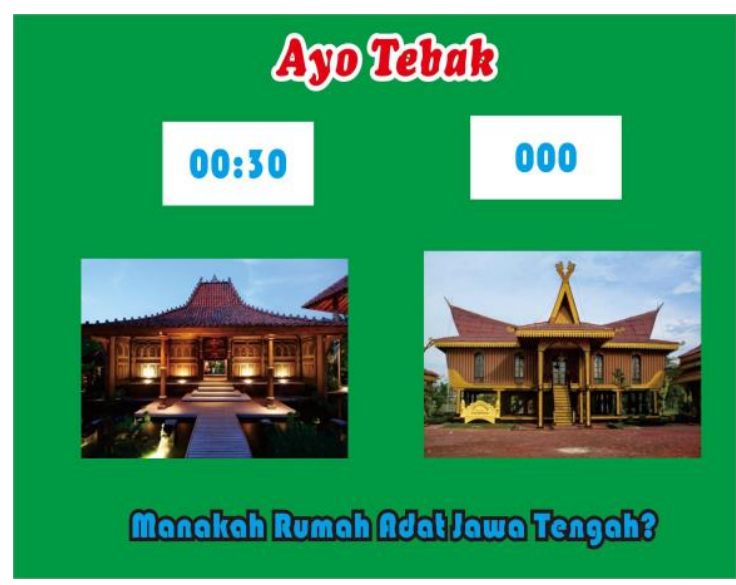

Gambar isi Menu Game Rumah Adat

\section{KESIMPULAN}

1. Sekolah SD Semesta saat ini telah mempunyai media pembelajaran yang berbasis multimedia sebagai sarana kegiatan belajar-mengajar di sekolah.

2. Media berbasis multimedia ini lebih efektif dan efisien dibanding mediamedia sebelumnya karena sangat membantu guru dan siswa dalam kegiatan belajar-mengajar di sekolah.

\section{Saran}

1. Supaya proses belajar-mengajar disekolah akan lebih efektif dan efesien sebaiknya penyampaian materi secara konvensional diganti dengan media pembelajaran yang berbasis multimedia yang komputerisasi walaupun secara bertahap, selain mempermudah penyampaian dan penerimaan materi, agar siswa akan terlatih dengan sistem komputerisasi sejak dini sesuai dengan perkembangan zaman.

2. Pada proses penelitian ini masih banyak kekurangan dikarenakan terbatasnya kemampuan peneliti dan masih banyak hal-hal yang kurang jelas.

\section{DAFTAR PUSTAKA}

[1] E. Sudarmilah and P. A. Wibowo, "khazanah informatika Aplikasi Augmented Reality Game Edukasi untuk Pengenalan Organ Tubuh Manusia," pp. 20-25.

[2] I. Muhammadiyah and M. I. M. Ngadirejan, "Indonesian Jurnal on Computer Science - Speed (IJCSS) 15 Vol 10 No 1 - Februari 2013 ijcss.unsa.ac.id," vol. 10, no. 1, pp. 26-30, 2013.

[3] G. Sagala, M. Mesran, and D. U. Sutiksno, "Perancangan Aplikasi Pembelajaran Pakaian Adat Asli Indonesia Berbasis Multimedia Dan Web Menerapkan Metode Computer Assisted Instruction ( CAI )," vol. 4, no. 4, pp. 12-15, 2017.

[4] I. Rizki et al., "Pengembangan Game Edukasi Pengenalan Budaya 
Indonesia ' Jelajah' Berbasis Android," pp. 1-5, 2015.

[5] H. S. Suratinoyo et al., "Cerita Rakyat Daerah Minahasa: Implementasi Short Film Animasi 3D dan dibutuhkan kemampuan."

[6] R. Wijayanto, "Perancangan Animasi Interaktif Pembelajaran Bahasa Inggris Untuk Kelas 2 Pada Mi Nurul Falah Ciater," vol. II, no. 1, pp. 1-11, 2014.

[7] E. Susanti, U. Tamansiswa, and S. Selatan, "Siswa Sekolah Menengah Pertama," no. 2, pp. 1-22, 2014.

[8] C. Agustina and T. Wahyudi, "Aplikasi Game Pendidikan Berbasis Android Untuk Memperkenalkan Pakaian Adat Indonesia," vol. 1, no. 1, pp. 1-8, 2015. 